\title{
Tau-protein concentrations are not elevated in cerebrospinal fluid of patients with progressive multifocal leukoencephalopathy
}

\author{
Nora Möhn ${ }^{1 \dagger}$, Yi Luo ${ }^{1 \dagger}$, Thomas Skripuletz ${ }^{1}$, Philipp Schwenkenbecher ${ }^{1}$, Inga Zerr², Peter Lange ${ }^{2}$ \\ and Martin Stangel ${ }^{1 *}$
}

\begin{abstract}
Progressive multifocal leukoencephalopathy (PML), caused by infection with John Cunningham polyoma virus (JCPyV) in immune-compromised patients, is a serious demyelinating disease of the central nervous system. This disease often leads to major neurological impairments and consecutive disability. No effective treatment for PML has been found as yet. As JCPyV-PCR of the cerebrospinal fluid (CSF) may be negative in some cases, a reliable diagnosis might prove to be difficult as well. So far, two case reports suggested CSF-tau to be a promising biomarker for PML. Our study included 10 patients with assured diagnosis of PML and varying underlying diseases. In all but one the CSFtau concentration was normal. Our results indicate that CSF-tau is not an appropriate biomarker for PML.
\end{abstract}

Keywords: Progressive multifocal leukoencephalopathy, Tau-protein, Biomarker, Cerebrospinal fluid, Immunosuppression

\section{Introduction}

PML is a central nervous system (CNS) demyelinating disease induced by the infection with John Cunningham polyoma virus (JCPyV). PML mostly occurs in immunecompromised patients, for example with acquired immune deficiency syndrome (80\%), hematologic malignancies (13\%), organ transplant recipients (5\%), and patients treated with immunosuppressive drugs (3\%) [1, 2]. The disease is rare, but is characterized by high mortality rates and long-term neurologic morbidity. The diagnosis of PML is generally based on clinical, imaging, laboratory, and histopathological features. The detection of JCPyV DNA in CSF in combination with appropriate clinical symptoms, and radiological characteristics contributes to a definite diagnosis of PML. In individual

\footnotetext{
*Correspondence: Stangel.Martin@mh-hannover.de

${ }^{\dagger}$ Nora Möhn and Yi Luo contributed equally to this work

${ }^{1}$ Department of Neurology, Hannover Medical School, Carl-Neuberg-Str.

1, 30625 Hannover, Germany

Full list of author information is available at the end of the article
}

cases the presence of characteristic pathoanatomic findings from a CNS biopsy specimen may be required to establish the correct diagnosis [3]. Undoubtfully, an early diagnosis and quick therapeutic approach to the immune deficiency could improve the prognosis. Reasons for a delayed diagnosis of PML may be (1) the diversity of its clinical symptoms depending on the lesion localization, (2) the lack of typical radiographic features in brain magnetic resonance imaging (MRI), and (3) the fact that JCPyV-PCR may be negative, especially at an early stage of disease. In case of clinical suspicion, an invasive brain biopsy might be required. Consequently, identification of potential biomarkers for PML is a clinical need for patients with clinical suspicion and negative CSF PCR.

Tau is a microtubule-associated protein predominantly expressed in CNS neurons and has been verified as an important factor in the formation and subsequent stabilization of microtubules, as well as for the organelle movement of axons and dendrites [4]. In recent years, immunohistochemical studies indicated that neuroaxonal degeneration and neurological inflammation may 
result in an increased release of tau from neurons and an enhanced phosphorylation of tau. Notably, tau protein in CSF has been recognized as an important biomarker for degenerative CNS diseases like Alzheimer's disease [5]. Besides neurodegenerative diseases some reports also suggest that the CSF concentrations of total tau ( $t$-tau) and phosphorylated tau (p-tau) are different between patients with viral or bacterial neurological infections compared with healthy individuals [6].

There is one case report which suggested that an elevated CSF t-tau may be a biomarker for PML. In this case of a patient with B-cell lymphoma associated PML $\mathrm{t}$-tau was excessively elevated in the CSF while $\mathrm{p}$-tau was rather low [7]. Another study, investigating CSF tau-concentrations in HIV patients, included one HIV+ patient with diagnosed PML who exhibited an elevated CSF tau-concentration. The authors of the study observed an association between elevated CSF tau and poor survival in HIV+ patients, but also pointed out that CSF tau was not increased in the majority of patients [8]. So far, there was no systematic investigation of $\mathrm{t}$-tau in the CSF of PML patients. We therefore studied t-tau and $\mathrm{p}$-tau concentrations in patients with PML and different underlying conditions leading to immunodeficiency.

\section{Methods}

\section{Measurement of CSF tau-concentrations}

All patients were treated at the Department of Neurology at Hannover Medical School. CSF samples were obtained via lumbar puncture in sitting position. After a centrifugation process all samples were frozen in aliquots within $2 \mathrm{~h}$ after lumbar puncture and stored at $-80^{\circ} \mathrm{C}$ until analysis. Tau- and p-tau-concentrations within the CSF were measured via solid-phase enzyme-linked immunosorbent assay (ELISA). For all analyses the ELISA-Kits INNOTEST hTAU Ag and INNOTEST PHOSPHO-TAU (INNOGENETICS, Heiden) were used and all measurements were performed according to the laboratory standards of the neurochemical laboratory at the University of
Göttingen. After a coating-step with a monoclonal antibody (AT120 or HT7, respectively) CSF-samples were added. Following several washing steps, samples were incubated with biotinylated antibodies (HT7 and BT2 or AT270bio, respectively). Antigen-antibody complexes were detected via color reaction between peroxidaselabelled streptavidin and a substrate solution. The reference range for CSF tau-concentrations is $80-450 \mathrm{pg} / \mathrm{ml}$. For CSF p-tau-concentrations, a maximum of $60 \mathrm{pg} / \mathrm{ml}$ is considered normal. Reference values are based on the 2001 publication by Sjögren and colleagues, who analyzed Tau-concentrations in CSF of 231 neurologically and psychiatrically healthy individuals aged between 21 and 93 years [9]. Furthermore, the local laboratory reference was considered as well.

The study was approved by the local institutional review board (Hannover Medical School, 2413-2014).

\section{Statistical analysis}

The continuous variables are represented as mean \pm SD. The association between concentrations of $\mathrm{t}$-tau, $\mathrm{p}$-tau and age, modified Rankin Scale (mRS) score, and the copy number of JCPyV DNA in PML patients was assessed using correlation analyses. Values of $\mathrm{P}<0.05$ were considered statistically significant. All statistical analyses were performed using the SPSS program (Version 24.0, IBM Statistics).

\section{Results \\ Patients characteristics}

A total of 10 patients were enrolled in the present study. Their baseline characteristics are summarized in Table 1 . Except of one patient, all were male with a median age of 56 years (range $31-77$ years). The cohort contained three patients with HIV infection, four suffered from neoplastic or myeloproliferative diseases, two patients with multiple sclerosis (MS) received natalizumab, and one patient was immunosuppressed with tacrolimus and mycophenolate mofetil due to liver transplant. JCPyV DNA was

Table 1 Demographics and clinical characteristics of PML patients

\begin{tabular}{|c|c|c|c|c|c|c|c|c|c|c|}
\hline Case & P1 & P2 & P3 & P4 & P5 & P6 & P7 & P8 & P9 & P10 \\
\hline Age (years) & 77 & 76 & 55 & 43 & 72 & 31 & 57 & 54 & 54 & 42 \\
\hline $\operatorname{Sex}(M=$ male $F=$ female $)$ & M & M & M & M & $M$ & M & M & $M$ & M & $\mathrm{F}$ \\
\hline UID & $B C$ & $\mathrm{NHL}$ & $C L L$ & MS & $\mathrm{LT}$ & HIV & HIV & MM & HIV & MS \\
\hline mRS after PML & 2 & 4 & 5 & 3 & 2 & 2 & 3 & 2 & 3 & 4 \\
\hline JCPyV DNA (c/ml) & 100.000 & 200.000 & 499 & 500 & $\begin{array}{l}\text { Neg. (brain } \\
\text { biopsy) }\end{array}$ & 1080 & 800 & 179 & 249 & 249 \\
\hline T-tau (pg/ml) & 332 & 374 & 218 & 190 & 121 & 568 & 87 & 239 & 389 & 118 \\
\hline P-tau (pg/ml) & 49 & 34 & 24 & 43 & 36 & 62 & 22 & 51 & 56 & 36 \\
\hline
\end{tabular}

UID underlying immunodeficiency, $m R S$ modified Rankin Scale, $B C$ bronchial carcinoma, NHL non-Hodgkin lymphoma, $C L L$ chronic lymphocytic leukemia, $M S$ multiple sclerosis treated with natalizumab, $L T$ liver transplant, $M M$ multiple myeloma, HIV human immunodeficiency virus 
Table 2 Correlation analysis with t-tau and p-tau

\begin{tabular}{lrrr}
\hline & \multicolumn{1}{l}{ Age } & \multicolumn{1}{l}{ MRS } & JCPyV DNA \\
\hline t-tau & & & \\
Correlation coefficient & -0.146 & -0.342 & -0.108 \\
$p$ & 0.688 & 0.333 & 0.799 \\
p-tau & & & \\
Correlation coefficient & -0.451 & 0.143 & -0.096 \\
$p$ & 0.191 & 0.694 & 0.821 \\
\hline
\end{tabular}

detectable via polymerase chain reaction (PCR) in CSF of 9 patients with values ranging from $<180$ to 200,000 copies/ml. In one patient PML was detected via stereotactic biopsy of the brain.

\section{Tau concentrations in CSF of PML patients}

The CSF t-tau levels were $270.6 \pm 145.3 \mathrm{pg} / \mathrm{ml}$ (mean \pm SD) and the CSF p-tau levels were $41.3 \pm 13.3 \mathrm{pg} /$ $\mathrm{ml}$ in patients with PML. In 1 of the 10 patients, the CSF t-tau level was slightly increased $(568 \mathrm{pg} / \mathrm{ml})$, whereas all other values were within normal range $(<450 \mathrm{pg} / \mathrm{ml})$. All patients exhibited normal CSF p-tau concentrations (normal range: $<61 \mathrm{pg} / \mathrm{ml}$ ). Due to the lack of a control group, CSF tau concentrations of our cohort have been compared with commonly accepted reference values (see "Methods").

There was no correlation of CSF t-tau or p-tau concentrations with age, $\mathrm{mRS}$ score, or the copy number of JCPyV DNA in PML patients (Table 2).

\section{Discussion}

One previously published case report suggested that the level of t-tau protein may be increased in the CSF of PML patients who suffer from B-cell lymphoma [7]. The authors implied that this might be a novel promising biomarker for the diagnosis of PML. To clarify this hypothesis, 10 PML patients were included in our study to measure the concentrations of $\mathrm{t}$-tau and p-tau in CSF via enzyme-linked immunosorbent assay. It is noteworthy that the $\mathrm{t}$-tau levels were normal in 9 of 10 patients and p-tau concentrations were normal in all patients. Their values did not correlate with age, JCPyV DNA in CSF, or severity of the disease. As PCR-negative PML is not very common only one PML-patient in our series was JCPyV-negative. Thus, a statistical comparison between JCPyV-negative and JCPyV-positive patients was not feasible. Compared with reference values of healthy individuals CSF tau-concentrations were not elevated in our PML patients regardless of their JCPyV-status. It seems extremely unlikely that PCR-negative PML patients will have other CSF tau/p-tau concentrations. Collectively, our data suggest that neither t-tau nor p-tau is a predictive biomarker for PML independent of the patient's JCPyV-status.

Our findings contradict the previously mentioned case report that showed increased $\mathrm{t}$-tau concentrations in CSF of a PML patient, and was supported by studies which suggested that axons may be injured or damaged by the loss of myelin protection [10]. In contrast to the previously published case report, we included more CSF samples from PML patients with different underlying diseases. It remains unclear why the t-tau concentrations were elevated in the previously published cases. We only can speculate that the patients suffered of unknown comorbidities.

This study has several limitations: first, this work is based on data from a single institution. Secondly, the number of analyzed CSF specimen is low, although this is the first study which measured CSF-tau concentrations in more than one PML patient. Nevertheless, our results are so clear-cut that investigation of more samples is not necessary.

In conclusion, CSF-tau protein does not meet the rigorous standards for a clinical biomarker for PML.

\section{Conclusion}

PML is a threatening disease in which early diagnosis is highly relevant. As JCPyV-PCR may be negative there is need for a reliable biomarker. We examined CSF-tau protein in a cohort of 10 PML positive patients. In conclusion, we can state that CSF-tau protein does not meet the rigorous standards for a clinical biomarker for PML.

\section{Abbreviations \\ PML: progressive multifocal leukoencephalopathy; JCPyV: John Cunningham polyoma virus; CSF: cerebrospinal fluid; CNS: central nervous system; MRI: magnetic resonance imaging; t-tau: total tau; p-tau: phospho-tau; ELISA: enzyme-linked immunosorbent assay; mRS: modified Rankin Scale; MS: multi- ple sclerosis; PCR: polymerase chain reaction.}

\section{Acknowledgements}

The authors thank Karin Fricke for excellent technical assistance.

\section{Authors' contributions}

NM, YL: acquisition and interpretation of data, writing of the manuscript. TS, PS: critical revision of manuscript for intellectual content. IZ, PL: supervision of analysis of CSF tau-concentrations, critical revision of manuscript for intellectual content. MS: study concept and design, critical revision of manuscript for intellectual content. All authors read and approved the final manuscript.

\section{Funding}

MSt is supported by the Deutsche Forschungsgemeinschaft through the Cluster of Excellence RESIST (EXC 2155).

\section{Availability of data and materials}

All data generated or analyzed during this study are included in this published article.

\section{Ethics approval and consent to participate}

Approval of the local institutional review board was given (Hannover Medical School, 2413-2014). 


\section{Competing interests}

The authors declare that they have no competing interests.

\section{Author details}

${ }^{1}$ Department of Neurology, Hannover Medical School, Carl-Neuberg-Str. 1, 30625 Hannover, Germany. ${ }^{2}$ Neurochemical Laboratory, Department of Neurology, University Medicine Göttingen, Robert-Koch-Str. 40, 37075 Göttingen Germany.

Received: 4 June 2019 Accepted: 5 August 2019

Published online: 05 September 2019

\section{References}

1. Tan CS, Koralnik IJ. Progressive multifocal leukoencephalopathy and other disorders caused by JC virus: clinical features and pathogenesis. Lancet Neurol. 2010;9:425-37.

2. Bag AK, Curé JK, Chapman PR, Roberson GH, Shah R. JC virus infection of the brain. AJNR Am J Neuroradiol. 2010;31:1564-76.

3. Berger JR, Aksamit AJ, Clifford DB, Davis L, Koralnik IJ, Sejvar JJ, et al. PML diagnostic criteria: consensus statement from the AAN. Neuroinfectious disease section. Neurology. 2013;80:1430-8.

4. Zetterberg H. Review: tau in biofluids-relation to pathology, imaging and clinical features. Neuropathol Appl Neurobiol. 2017;43:194-9.
5. Obulseu M, Venu R, Somashekhar R. Tau mediated neurodegeneration: an insight into Alzheimer's disease pathology. Neurochem Res. 2011:36:1329-35.

6. Czupryna P, Mroczko B, Pancewicz S, et al. Assessment of the tau protein concentration in patients with tick-borne encephalitis. Eur J Clin Microbiol Infect Dis. 2019;38(3):479-83.

7. Brüggemann N, Gottschalk S, Körtke D, et al. Excessively increased CSF tau in progressive multifocal leukoencephalopathy. Clin Neurol Neurosurg. 2012;114(6):762-4.

8. Green AJ, Giovannoni G, Hall-Craggs MA, Thompson EJ, Miller RF. Cerebrospinal fluid tau concentrations in HIV infected patients with suspected neurological disease. Sex Transm Infect. 2000;76:443-6.

9. Sjögren M, Vanderstichele H, Ågren H, Zachrisson O, Edsbagge M, et al. Tau and $A \beta 42$ in cerebrospinal fluid from healthy adults 21-93 years of age: establishment of reference values. Clin Chem. 2001;47:1776-81.

10. Williamson EML, Berger JR. Diagnosis and treatment of progressive multifocal leukoencephalopathy associated with multiple sclerosis therapies. Neurotherapeutics. 2017;14(4):961-73.

\section{Publisher's Note}

Springer Nature remains neutral with regard to jurisdictional claims in published maps and institutional affiliations.
Ready to submit your research? Choose BMC and benefit from:

- fast, convenient online submission

- thorough peer review by experienced researchers in your field

- rapid publication on acceptance

- support for research data, including large and complex data types

- gold Open Access which fosters wider collaboration and increased citations

- maximum visibility for your research: over $100 \mathrm{M}$ website views per year

At BMC, research is always in progress.

Learn more biomedcentral.com/submissions 